\title{
Fracture Energy of High-Strength Concrete
}

\author{
by David Darwin, Shawn Barham, Rozalija Kozul, and Shuguang Luan
}

\begin{abstract}
The effects of water-cementitious materials ratio, age, and aggregate type on the compressive strength, flexural strength, and fracture energy of concretes with compressive strengths ranging from 20 to $99 \mathrm{MPa}$ (2900 to 14,400 psi) are studied. Concrete mixtures contain either basalt or crushed limestone aggregate with maximum sizes of 12 or $19 \mathrm{~mm}(1 / 2$ or 3/4 in.). Mixtures are tested at ages ranging from 5 to 180 days and have water-cementitious (w/cm) ratios ranging from 0.24 to 0.50 . High-strength concrete containing the higher-strength, basalt coarse aggregate attains higher compressive and flexural strengths than high-strength concrete containing limestone. The compressive and flexural strengths of medium and normalstrength concretes ( $\mathrm{f}_{\mathrm{c}}{ }^{\prime}$ up to approximately $60 \mathrm{MPa}[9000 \mathrm{psi}]$ ) are affected little by aggregate type. Concrete containing basalt yields significantly higher fracture energy than concrete containing limestone, with fracture energy governed principally by aggregate properties, independent of compressive strength, $\mathrm{w} / \mathrm{cm}$ ratio, and age. Overall, as compressive strength increases, the energy stored in the material at the peak tensile load increases while the ability of the material to dissipate energy remains approximately constant. The result is increasingly brittle behavior as compressive strength increases.
\end{abstract}

Keywords: aggregates; compressive strength; flexural strength; fracture mechanics; high-strength concrete; water-cementitious materials ratio.

\section{INTRODUCTION}

When concrete fails in tension, its behavior is characterized by both the peak stress and the energy required to fully open a crack. Fracture energy $G_{f}$ is the energy required to form a crack of unit area. While the peak stress establishes the tensile strength of the material, the fracture energy controls the ease with which a crack will propagate. Recent research (Tholen and Darwin 1996; Collins and Kuchma 1999; Zuo and Darwin 2000) indicates that fracture energy plays an increasingly important role in the behavior of reinforced concrete members when tension is resisted by concrete alone. Tests show that both the bond strength between reinforcing steel and concrete and the shear strength of concrete increases more slowly than $\sqrt{f_{c}^{\prime}}$ when $f_{c}^{\prime}>50 \mathrm{MPa}(7000 \mathrm{psi})$, even though the tensile strength of the concrete increases at least as rapidly as $\sqrt{f_{c}^{\prime}}$ (Ahmad and Shah 1985). In particular, Zuo and Darwin (2000) demonstrated that the splice strength of reinforcing bars not confined by transverse reinforcement increases with ${f_{c}}^{\prime 0.25}$ for $29 \mathrm{MPa}(4250 \mathrm{psi}) \leq f_{c}^{\prime} \leq 108 \mathrm{MPa}$ $(15,650 \mathrm{psi})$. In shear tests of full-scale reinforced concrete beams without transverse reinforcement, Collins and Kuchma (1999) observed that there was no increase in shear strength for $f_{c}^{\prime}>50 \mathrm{MPa}$ (7250 psi), and, in fact, there was an $18 \%$ decrease in shear strength between $f_{c}^{\prime}=36 \mathrm{MPa}$ (5700 psi) and $99 \mathrm{MPa}(14,400 \mathrm{psi})$. The reason for the relatively poor performance of high-strength concrete in bond and shear is that these structural properties involve crack propagation and are thus not controlled by tensile strength alone.

The goal of this research is to investigate the relationships between compressive strength, flexural strength, fracture energy, water-cementitious materials ratio $(\mathrm{w} / \mathrm{cm})$, age, and aggregate type. The compressive and tensile strengths of concrete increase with decreasing $\mathrm{w} / \mathrm{cm}$ and increasing age. For normal weight aggregates, properties have relatively little effect on the strength of normal-strength concretes, but play an increasingly important role as the compressive and tensile strengths increase. The relationship of fracture energy to these properties is less clear, with most studies showing a relative insensitivity to $w / \mathrm{cm}$ and age, and a greater sensitivity to aggregate type than is observed for compressive and tensile strength. Full details of the study are presented by Kozul and Darwin (1997) and Barham and Darwin (1999).

\section{RESEARCH SIGNIFICANCE}

This study is significant because it provides an explanation for the relatively poor structural performance of highstrength reinforced concrete members under load regimes in which the tensile properties of concrete play an important role. Recent studies (Collins and Kuchma 1999; Zuo and Darwin 2000) have demonstrated that high-strength concretes provide significantly lower bond and shear strengths than would be expected based on relationships developed for concretes with $f_{c}^{\prime}<50 \mathrm{MPa}(7000 \mathrm{psi})$.

\section{EXPERIMENTAL WORK}

Concrete specimens were tested to determine the relationships between compressive strength, flexural strength, and fracture energy as a functions of $w / \mathrm{cm}$, age, and aggregate type. The tests were carried out in two series. Series I (Kozul and Darwin 1997) was part of a larger study to determine the effect of concrete compressive strength and reinforcing bar properties on the bond strength between reinforcing steel and concrete (Darwin et al. 1996a, 1996b; Zuo and Darwin 2000). Series I included aggregate sizes of 12 and $19 \mathrm{~mm}(1 / 2$ and $3 / 4 \mathrm{in}$.) and $w / \mathrm{cm}$ ratios of 0.24 to 0.50 . Tests were carried out at ages that were representative of those used for the bond test specimens, five days for normal-strength concrete and 94 to 164 days for high-strength concrete. Series II (Barham and Darwin 1999) tests used $19 \mathrm{~mm}$ (3/4 in.) aggregate and three concrete strength categories (normal, medium, and high) obtained using $w / \mathrm{cm}$ ratios ranging from 0.25 to 0.46 . In Series II, the specimens were tested at ages of 7, 28, 56, 90, and 180 days. Crushed basalt and limestone coarse aggregates were used in both series.

\section{Materials}

Type I portland cement was used in all mixtures. Mediumstrength concrete also contained Class $\mathrm{C}$ fly ash, while

ACI Materials Journal, V. 98, No. 5, September-October 2001

MS No. 01-063 received February 26, 2001, and reviewed under Institute publication policies. Copyright (C) 2001, American Concrete Institute. All rights reserved, including the making of copies unless permission is obtained from the copyright proprietors. Pertinent discussion will be published in the July-August 2002 ACI Materials Journal if received by April 1, 2002. 
David Darwin, FACI, is the Deane E. Ackers Professor of Civil Engineering and Director of the Structural Engineering and Materials Laboratory at the University of Kansas, Lawrence, Kans. He is a past member of the Board of Direction and the Technical Activities Committee and is past-president of the Kansas Chapter of ACI. Darwin is also past-chairman of the Publications Committee and the Concrete Research Council, and a member and past-chairman of ACI Committee 224, Cracking. He chairs the TAC Technology Transfer Committee and ACI Committee 408, Bond and Development of Reinforcement, and serves on ACI Committee 446, Fracture Mechan ics; ACI-ASCE Committees 445, Shear and Torsion; and 447, Finite Element Analysis of Reinforced Concrete Structures. He is a recipient of the Arthur R. Anderson and ACI Structural Research Awards.

Shawn Barham is a structural engineer with Burns \& McDonnell International in Kansas City, Mo. He received his BS and MS in civil engineering from the University of Kansas.

Rozalija Kozul is a project engineer with the Penta Building Group in Las Vegas, Nev. She received her BS and MS in civil engineering from the University of Kansas.

Shuguang Luan is an associate professor of civil engineering at the Dalian Fishery College, Peoples Republic of China, and was a visiting scholar at the University of Kansas from 1997 to 1998.

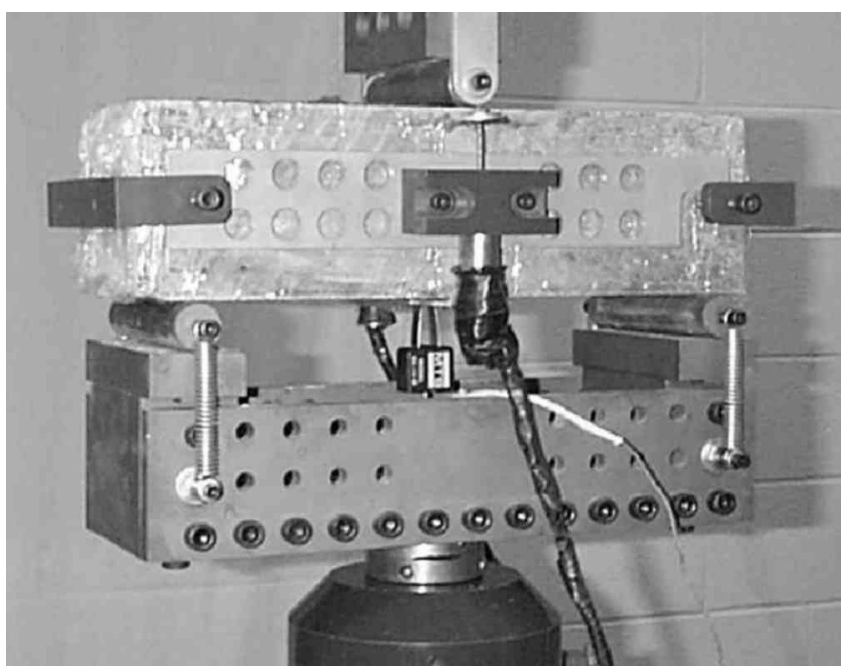

Fig. 1-Fracture energy test apparatus using closed-loop servohydraulic testing system.

high-strength concrete contained fly ash and compacted silica fume. The basalt coarse aggregate had a bulk specific gravity (ssd) of 2.64, an absorption (dry) of $0.4 \%$, a compressive strength (measured on a $25 \mathrm{~mm}$ square $\mathrm{x} 75 \mathrm{~mm}$ [1 in. square $x 3$ in.] prism) of $340 \mathrm{MPa}(50,000 \mathrm{psi})$, and a modulus of elasticity of $69 \mathrm{GPa}(10,000,000 \mathrm{psi})$. The limestone in Series I had a bulk specific gravity (ssd) of 2.58, an absorption (dry) of $2.7 \%$, a compressive strength of $100 \mathrm{MPa}$ $(15,000 \mathrm{psi})$, and a modulus of elasticity of $35 \mathrm{GPa}$ $(5,000,000 \mathrm{psi})$. The limestone in Series II had a bulk specific gravity (ssd) of 2.54 and an absorption (dry) of $3.9 \%$; the limestone in Series II was not tested for strength. The fine aggregate used in the study was river sand with a bulk specific gravity (ssd) of 2.61, an absorption (dry) of $0.5 \%$, and a fineness modulus of 2.60. A Type A normal-range water reducer and a Type $\mathrm{F}$ high-range water-reducing admixture were used. Mixture proportions are summarized in Table 1.

\section{Specimens}

Concrete was batched in a counter-current pan mixer. 100 x 100 × $350 \mathrm{~mm}(4 \times 4 \times 14$ in.) prismatic specimens were used for all tests. Forms were filled with the long dimension in the vertical direction. The concrete was consolidated in three equal layers, rodded 25 times each with a $16 \mathrm{~mm}(5 / 8 \mathrm{in}$.) tamping rod. After rodding each layer, the forms were struck smartly 10 to 15 times with a rubber mallet. Following consolidation, the forms were sealed and stored in a horizontal position at 20 to $24 \mathrm{C}$ ( 68 to $76 \mathrm{~F}$ ) for $48 \mathrm{~h}$. The molds were then removed and the specimens placed in lime-saturated water at 21 to $24 \mathrm{C}$ ( 70 to $76 \mathrm{~F})$. At least $24 \mathrm{~h}$ before the compressive specimens were tested, $25 \mathrm{~mm}$ ( $1 \mathrm{in}$.) was removed form each end using a high-speed masonry saw to achieve a $3: 1$ length-width ratio and capped with $1.6 \mathrm{~mm}$ (1/16 in.) layer of sulfur capping compound. The fracture energy specimens were prepared by cutting a $25 \mathrm{~mm}$ ( 1 in.) deep by $3 \mathrm{~mm}$ (1/8 in.) wide notch on one side at the midpoint perpendicular to the long direction. The specimens were then placed back in the lime-saturated water until the time of test. Specimens were covered with plastic wrap after removal from the water to minimize moisture loss during the test.

\section{Testing}

The compression tests were performed in accordance with ASTM C 39 (1996) using an 1800 kN (400 kip) capacity hydraulic testing machine at a loading rate of 0.14 to $0.34 \mathrm{MPa} / \mathrm{s}$ (20 to $50 \mathrm{psi} / \mathrm{s}$ ) until failure. The 3:1 height-width ratio placed the center region of the specimen in uniaxial compression.

The flexure specimens were loaded at an extreme fiber stress rate between 0.86 and $1.21 \mathrm{MPa} / \mathrm{min}$ (125 to $175 \mathrm{psi} / \mathrm{min}$ ) in accordance with ASTM C 293 (1994), using centerpoint loading in a $1800 \mathrm{kN}$ (400 kip) machine for Series I and a $150 \mathrm{kN}$ (35 kip) closed-loop servohydraulic testing system for Series II.

The fracture energy test followed the guidelines established by RILEM (1985) using a closed-loop testing machine under crack mouth opening displacement (CMOD) control (Fig. 1). Prior to the test, small regions on the bottom surface of the concrete on either side of the notch were dried using a hair dryer on low heat. Two steel plates with lips to fit into the sawed notch were attached on both sides of the notch using a rapid-drying glue. The clip gage used to measure the CMOD was then placed between knife edges attached to the steel plates. Two steel nails were then glued on both sides near the top of the specimen at midspan to hold the cores of two linear variable differential transformers (LVDTs) used to measured deflection. The cores were supported by washers suspended by the nails. The core housings of the LVDTs were held by aluminum bars screwed to the concrete at the mid-depth of the beam over the supports. Deflection was measured in this way so as not to include the effects of local specimen deformations at the support and load points. A data acquisition system was used to record load, CMOD, and deflection. A constant CMOD rate of $0.08 \mathrm{~mm} / \mathrm{min}(0.003 \mathrm{in.} / \mathrm{min})$ was set so that the peak load would be attained in approximately $30 \mathrm{~s}$. Tests lasted between 15 and $50 \mathrm{~min}$, depending on aggregate type, specimen age, and $w / \mathrm{cm}$.

\section{RESULTS AND EVALUATION}

The test results and comparisons of the compression, flexure, and fracture energy tests are presented. Where appropriate, the results for Series I and Series II are combined. Because of the matching ages at the time of test, most comparisons are illustrated using the results from Series II. Test results are summarized in Tables 2(a) and (b) for Series I and II, respectively. 
Table 1-Concrete mixture proportions ( $\mathrm{m}^{3}$ batch), slump, and test age

\begin{tabular}{|c|c|c|c|c|c|c|c|c|c|c|c|c|}
\hline $\begin{array}{c}\text { Concrete } \\
\text { type }^{*}\end{array}$ & Batches $^{\dagger}$ & $w / \mathrm{cm}^{\ddagger}$ & Water, $\mathrm{kg}$ & $\begin{array}{c}\text { Cement, } \\
\mathrm{kg}\end{array}$ & $\begin{array}{c}\text { Fly ash, } \\
\text { kg }\end{array}$ & $\begin{array}{c}\text { Silica } \\
\text { fume, } \mathrm{kg}\end{array}$ & $\begin{array}{c}\text { Fine } \\
\text { aggregate } \\
\text { (SSD), kg }\end{array}$ & $\begin{array}{c}\text { Coarse } \\
\text { aggregate } \\
\text { (SSD), kg }\end{array}$ & $\begin{array}{c}\text { Type A } \\
\text { admixture, L }\end{array}$ & $\begin{array}{c}\text { Type F } \\
\text { admixture, L }\end{array}$ & $\begin{array}{c}\text { Slump, } \\
\mathrm{mm}\end{array}$ & $\begin{array}{c}\text { Test age, } \\
\text { days }\end{array}$ \\
\hline \multicolumn{13}{|c|}{ Series I } \\
\hline \multirow{3}{*}{ NB } & $19 \mathrm{~h}$ & 0.50 & 164 & 327 & - & - & 775 & 1105 & - & - & 100 & 5 \\
\hline & $12 \mathrm{~h}$ & 0.50 & 164 & 327 & - & - & 773 & 1105 & - & - & 80 & 5 \\
\hline & 121 & 0.50 & 164 & 327 & - & - & 885 & 994 & 0.8 & - & 80 & 5 \\
\hline \multirow{2}{*}{ NL } & $12 \mathrm{~h}$ & 0.50 & 164 & 327 & - & - & 765 & 1090 & 0.7 & - & 100 & 5 \\
\hline & 121 & 0.50 & 164 & 327 & - & - & 888 & 973 & 1.0 & - & 100 & 5 \\
\hline \multirow{7}{*}{ HB } & 19h.1 & 0.26 & 116 & 411 & 24 & 49 & 714 & 1105 & 2.1 & 13.2 & 230 & 137 \\
\hline & $19 \mathrm{~h} .2$ & 0.26 & 116 & 411 & 24 & 49 & 714 & 1098 & 2.1 & 11.0 & 240 & 116 \\
\hline & $12 \mathrm{~h} .1$ & 0.24 & 107 & 412 & 24 & 49 & 743 & 1102 & 2.1 & 14.4 & 230 & 164 \\
\hline & $12 \mathrm{~h} .2$ & 0.26 & 105 & 410 & 24 & 48 & 739 & 1096 & 2.1 & 24.2 & 240 & 149 \\
\hline & $12 \mathrm{~h} .3$ & 0.28 & 116 & 412 & 24 & 49 & 714 & 1101 & 2.1 & 26.6 & 230 & 119 \\
\hline & 121.1 & 0.28 & 105 & 407 & 24 & 48 & 846 & 986 & 2.1 & 36.6 & 230 & 160 \\
\hline & 121.2 & 0.27 & 116 & 413 & 24 & 49 & 824 & 985 & 2.1 & 21.1 & 240 & 117 \\
\hline \multirow{3}{*}{$\mathrm{HL}$} & $12 \mathrm{~h} .1$ & 0.26 & 116 & 410 & 24 & 48 & 716 & 1074 & 2.4 & 10.5 & 240 & 148 \\
\hline & $12 \mathrm{~h} .2$ & 0.26 & 117 & 411 & 24 & 49 & 721 & 1071 & 2.4 & 11.6 & 240 & 111 \\
\hline & 121 & 0.27 & 117 & 413 & 24 & 49 & 829 & 964 & 2.4 & 19.9 & 220 & 94 \\
\hline \multicolumn{13}{|c|}{ Series II } \\
\hline NB & $\begin{array}{c}1,2, \\
1-2,3\end{array}$ & 0.46 & 164 & 356 & - & - & 790 & 1054 & - & - & $\begin{array}{c}80,100,-, \\
70\end{array}$ & 7 to $180^{\S}$ \\
\hline $\mathrm{NL}$ & 1,2 & 0.46 & 164 & 356 & - & - & 813 & 991 & - & - & 110,110 & 7 to $180^{\S}$ \\
\hline MB & 1,2 & 0.351 & 148 & 360 & 63 & - & 764 & 1054 & 0.4 & - & 110,120 & 7 to $180^{\S}$ \\
\hline ML & 1,2 & 0.35 & 148 & 360 & 63 & - & 787 & 991 & - & - & 130,100 & 7 to $180^{\S}$ \\
\hline HB & $1,2,3$ & $\begin{array}{l}0.266, \\
0.280 \\
0.261\end{array}$ & 133 & 470 & 28 & 55 & 683 & 1054 & 1.6 & $\begin{array}{c}18.1,29.6 \\
14.8\end{array}$ & $\begin{array}{c}170,160 \\
170\end{array}$ & 7 to $180^{\S}$ \\
\hline $\mathrm{HL}$ & 1,2 & $\begin{array}{l}0.250, \\
0.254\end{array}$ & 133 & 470 & 28 & 55 & 707 & 991 & 1.6 & $5.8,9.1$ & 180,240 & 7 to $180^{\S}$ \\
\hline
\end{tabular}

${ }^{*} \mathrm{~N}=$ normal-strength concrete; $\mathrm{M}=$ medium-strength concrete; $\mathrm{H}=$ high-strength concrete; $\mathrm{B}=$ basalt aggregate; and $\mathrm{L}=$ limestone aggregate.

$\dagger 12,19=12,19 \mathrm{~mm}$ maximum size aggregate; $\mathrm{h}, \mathrm{l}=\mathrm{high}$, low coarse aggregate content.

${ }^{\ddagger} \mathrm{w} / \mathrm{cm}$ = water-cementitious materials ratio; includes water in admixtures.

$\S_{\text {Test ages }}=7,28,56,90$, and 180 days.

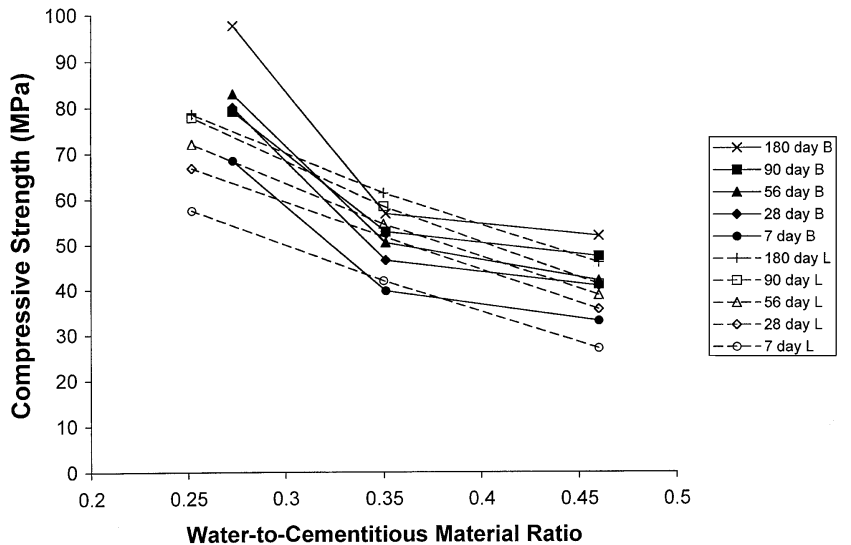

Fig. 2-Average compressive strength versus average $\mathrm{w} / \mathrm{cm}$ for concretes in Series II ( $B=$ basalt; $L=$ limestone $)(1 \mathrm{MPa}=$ $145 \mathrm{psi})$.

\section{Compressive strength}

Compressive strength $f_{c}^{\prime}$ is plotted versus $w / \mathrm{cm}$ and age for the Series II specimens in Fig. 2. The figure shows that basalt and limestone produce similar compressive strengths for both the normal and the medium-strength concretes. The basalt, however, produces significantly greater strengths than the limestone (with the exception of the tests at 90 days) for high-strength concrete. The greatest difference is observed at 180 days, where the basalt high-strength specimens average $25 \%$ higher compressive strengths than those containing limestone. These observations match those of other researchers (Kaplan 1959; Giaccio et al. 1992; Ozturan and Cecen 1997) who found that higher-strength aggregates have a progressively beneficial effect as compressive strength increases. The reason is that the cement paste matrix is denser and stiffer in high-strength concrete, resulting in greater compatibility in strength and stiffness between the cement paste and the aggregate, thus leading to lower stress concentrations at the matrix-aggregate interface. The tensile strength of the aggregate, rather than the interfacial strength (as in normal-strength concrete), becomes the weak link. Because of this, the compressive strength of high-strength concrete can be limited by aggregate strength. For the medium and normal-strength concretes, the two aggregates result in similar strengths, with limestone actually producing higher compressive strengths in the medium-strength concrete (Fig. 2 and Table 2[b]).

The appearance of the failure surfaces of the specimens depends on the aggregate type. In normal-strength concrete with both types of aggregate, the fracture surface was torturous, with significant crack branching. The basalt concrete had virtually no fractures through the coarse aggregate, while the limestone concrete showed evidence of some 
Table 2(a)-Concrete properties for Series I

\begin{tabular}{|c|c|c|c|c|c|c|c|c|c|c|}
\hline \multirow[b]{2}{*}{ Group } & \multirow[b]{2}{*}{ Age, days } & \multicolumn{3}{|c|}{ Compressive strength, $\mathrm{MPa}$} & \multicolumn{3}{|c|}{ Flexural strength, MPa } & \multicolumn{3}{|c|}{ Fracture energy, $\mathrm{N} / \mathrm{m}$} \\
\hline & & Specimen 1 & Specimen 2 & Specimen 3 & Specimen 1 & Specimen 2 & Specimen 3 & Specimen 1 & Specimen 2 & Specimen 3 \\
\hline NB-19h & 5 & 29.6 & 29.4 & 31.4 & 5.6 & 5.7 & 6.1 & 230 & 220 & 227 \\
\hline NB-12h & 5 & 27.6 & 27.6 & 28.3 & 5.4 & 5.7 & 5.6 & 198 & 164 & 193 \\
\hline NB-121 & 5 & 24.1 & 26.9 & 25.0 & 5.8 & 4.8 & 4.8 & 182 & 184 & 182 \\
\hline NL-12h & 5 & 30.3 & 30.5 & 30.7 & 5.7 & 5.4 & 5.5 & 70 & 67 & 60 \\
\hline NL-121 & 5 & 29.7 & 29.2 & 28.8 & 5.7 & 5.7 & 5.7 & 53 & 48 & 66 \\
\hline HB-19h.1 & 137 & 82.7 & 81.5 & 78.3 & 10.3 & 12.1 & - & 136 & 137 & 187 \\
\hline HB-19h.2 & 116 & 79.5 & 76.7 & 76.9 & 10.2 & 9.3 & 10.1 & 215 & 140 & 152 \\
\hline HB-12h.1 & 164 & 92.6 & 93.0 & 103.4 & 13.0 & 12.6 & 13.0 & 148 & 164 & 151 \\
\hline HB-12h. 2 & 149 & 81.9 & 84.5 & 79.1 & 11.1 & 10.1 & 11.4 & 169 & 194 & 151 \\
\hline HB-12h.3 & 119 & 80.6 & 80.8 & 78.9 & 10.1 & 10.5 & 10.0 & 173 & 206 & 155 \\
\hline HB-121.1 & 160 & 93.1 & 94.3 & - & 10.9 & 11.5 & - & 167 & - & - \\
\hline HB-121.2 & 117 & 60.4 & 66.1 & 61.2 & 9.0 & 8.8 & 9.2 & 158 & 203 & 127 \\
\hline HL-12h.1 & 148 & 80.2 & 82.3 & 76.4 & 8.4 & 8.9 & 8.9 & - & - & - \\
\hline HL-12h. 2 & 111 & 74.2 & 67.2 & 71.4 & 7.9 & 8.3 & 8.1 & 69 & 63 & 59 \\
\hline HL-121 & 94 & 71.6 & 71.2 & 68.8 & 8.1 & 9.0 & 8.5 & 68 & 69 & 59 \\
\hline
\end{tabular}

Table 2(b)-Concrete properties for Series II

\begin{tabular}{|c|c|c|c|c|c|c|c|c|c|c|c|c|c|c|c|}
\hline \multirow[b]{2}{*}{ Group } & \multicolumn{5}{|c|}{ Compressive strength, MPa } & \multicolumn{5}{|c|}{ Flexural strength, MPa } & \multicolumn{5}{|c|}{ Fracture energy, $\mathrm{N} / \mathrm{m}$} \\
\hline & 7 days & 28 days & 56 days & 90 days & 180 days & 7 days & 28 days & 56 days & 90 days & 180 days & 7 days & 28 days & 56 days & 90 days & 180 days \\
\hline NB1 & 33.8 & 38.0 & 42.3 & 44.3 & 49.7 & 4.8 & 6.4 & 5.7 & 6.0 & 5.7 & 100 & 106 & 133 & 133 & 136 \\
\hline NB2 & 30.1 & 41.9 & 39.0 & 46.9 & 50.8 & 4.6 & 6.3 & 5.8 & 5.5 & 5.3 & 143 & 127 & 140 & 202 & 133 \\
\hline NB1-2 & 35.7 & 42.7 & 44.9 & 51.0 & 55.2 & 5.2 & 6.7 & 5.6 & 5.7 & 5.8 & 131 & 106 & 131 & 161 & 138 \\
\hline NB3 & 35.4 & 42.8 & - & - & - & 5.7 & 6.4 & - & - & - & 131,110 & $\begin{array}{c}106, \\
128,120\end{array}$ & - & - & - \\
\hline NL1 & 20.1 & 26.0 & 30.5 & 33.4 & 39.9 & 3.8 & 4.6 & 4.5 & 6.1 & 6.7 & 44 & 42 & 52 & 45 & 49 \\
\hline NL2 & 34.0 & 45.4 & 47.2 & 49.0 & 52.1 & 5.7 & 6.0 & 6.5 & 7.0 & 7.5 & 42 & 45 & 44 & 48 & 48 \\
\hline MB1 & 40.0 & 50.4 & 51.6 & 52.9 & 55.4 & 6.2 & 7.3 & 7.3 & 7.1 & 6.9 & 146 & 141 & 118 & 162 & 160 \\
\hline MB2 & 39.6 & 42.6 & 49.1 & 52.8 & 58.1 & 5.7 & 7.2 & 7.0 & 6.7 & 6.7 & 139 & 112 & 145 & 167 & 117 \\
\hline ML1 & 38.8 & 47.0 & 50.2 & 53.3 & 56.0 & 5.7 & 6.3 & 6.3 & 6.4 & 6.6 & 45 & 45 & 56 & 61 & 63 \\
\hline ML2 & 45.1 & 56.5 & 58.9 & 63.5 & 66.6 & 6.4 & 7.1 & 7.3 & 7.3 & 7.5 & 55 & 63 & 57 & 66 & 65 \\
\hline HB1 & 71.5 & 78.2 & 87.2 & 76.5 & 96.6 & 8.9 & 11.7 & 11.9 & 12.1 & 12.6 & 116 & 106 & 127 & 119 & 117 \\
\hline HB2 & 65.3 & 81.9 & 78.6 & 81.7 & 98.7 & 10.2 & 11.2 & 10.7 & 12.2 & 13.5 & 132 & 104 & 140 & 113 & 128 \\
\hline HB3 & 65.6 & 85.4 & - & - & - & 8.3 & 10.9 & - & - & - & 127,137 & $\begin{array}{c}103, \\
109,142 \\
\end{array}$ & - & - & - \\
\hline HL1 & 51.2 & 66.6 & 67.5 & 70.9 & 71.3 & 5.7 & 7.1 & 7.3 & 7.5 & 7.6 & 28 & 50 & 39 & 40 & 45 \\
\hline HL2 & 63.7 & 66.9 & 76.5 & 84.7 & 85.7 & 6.9 & 7.6 & 7.7 & 7.7 & 7.8 & 43 & 42 & 43 & 41 & 36 \\
\hline
\end{tabular}

transgranular fracture. In high-strength concrete, the branching was similar, but less severe than in normal-strength concrete. There was, however, a large increase in the fracture of coarse aggregate particles. In the basalt concrete, most, but not all, of the coarse aggregate fractured. The limestone concrete had complete transgranular fracture, leaving the crack surface less torturous than in the basalt concrete and the smoothest overall. The medium-strength concrete had fracture surfaces that were a composite of those observed in normal and high-strength concrete.

\section{Flexural strength}

Flexural strength is plotted versus $w / \mathrm{cm}$ and age in Fig. 3. As with compressive strength (Fig. 2), the basalt coarse aggregate provided significantly higher values for the modulus of rupture $R$ than the limestone for the high-strength concrete (61\% greater at 7 days and $92 \%$ greater at 180 days), but similar values for the medium and normal-strength concretes. The fracture surfaces in the flexural specimens were similar to those observed in the compression tests, although there was slightly more transgranular fracture in the flexural specimens. Flexural strength increased with age more slowly than compressive strength.

\section{Fracture energy}

Fracture energy is the energy dissipated per unit area during the formation of a crack. The energy is dissipated within the fracture process zone, the region in front of a crack tip where the stress decreases as the crack opens. The area of fracture is the projected area on a plane perpendicular to the direction of stress. A schematic is presented in Fig. 4.

In the current study, fracture energy is determined using a notched beam in three-point bending. The average deflection is measured at the centerline of the beam. Load-deflection curves are plotted, with the energy $W_{0}$ representing the area under the curve.

RILEM (1985) and Hillerborg (1985) suggest that fracture energy be calculated using the following expression 


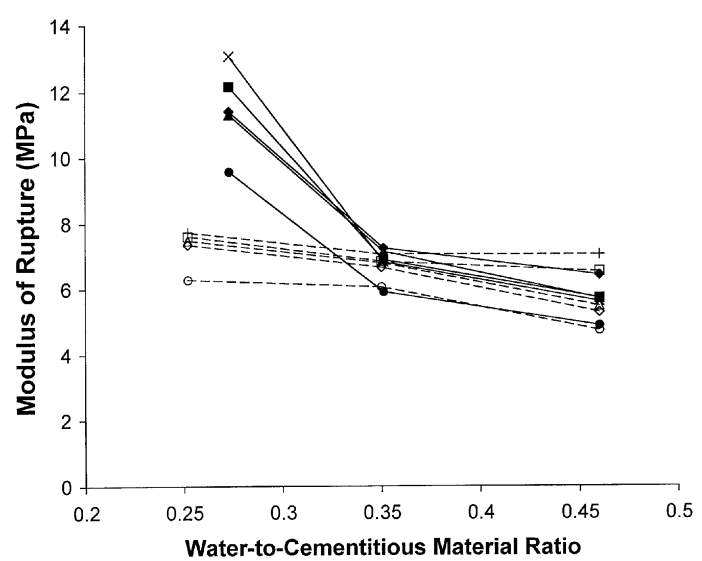

Fig. 3-Average modulus of rupture versus average $\mathrm{w} / \mathrm{cm}$ for concretes in Series II ( $B=$ basalt; $L=$ limestone) (1 MPa $=145 \mathrm{psi}$ ).

$$
G_{f}=\left(W_{0}+m g \delta_{f}\right) / A
$$

where $G_{f}=$ fracture energy (N-m or lb-in.); $W_{0}=$ area under the load-deflection curve (N-m or lb-in.); $m=m_{1}+2 m_{2}(\mathrm{~kg}$ or slug); $m_{1}=$ mass of the beam between the supports; $m_{2}=$ mass of the loading frame not attached to the load machine that follows the specimen until failure; $g=$ acceleration due to gravity; $\delta_{f}=$ final deflection of the beam ( $\mathrm{m}$ or in.); and $A$ $=$ cross-sectional area of the beam above the notch $\left(\mathrm{m}^{2}\right.$ or in. ${ }^{2}$.

The need for the term $m g \delta_{f}$ results from the fact that the imposed load from the machine is not the only load acting on the specimen during the test; the weight of the specimen between the supports and the weight of the testing equipment supported by the specimen also play a role. Therefore, the measured load-deflection curve does not account for the full load on the beam and thus does not reflect the total energy necessary to cause fracture.

A hypothetically complete load-deflection curve is shown in Fig. 4. $P_{1}$ is the additional load caused by the weight of the specimen $0.5 m_{1} g$ and the weight of loading equipment $m_{2} g$.

The total energy required to fully fracture the specimen is

$$
W=W_{0}+W_{1}+W_{2}
$$

where $W_{1}=P_{1} \delta_{f}=\left(0.5 m_{1}+m_{2}\right) g \delta_{f}=0.5 m g \delta_{f}$.

Hillerborg (1985) demonstrated that $W_{2}$ is approximately equal to $W_{1}$, making the total energy

$$
W=W_{0}+2 P_{1} \delta_{f}=W_{0}+m g \delta_{f}
$$

This total is divided by the projected area of fracture $A$ to give the fracture energy $G_{f}$.

Figure 5 compares the load-deflection curves from fracture tests of normal-strength concretes containing basalt and limestone coarse aggregates in Series I. The area under the curve for the concrete containing basalt is significantly greater than that for the concrete containing limestone. The concretes exhibit nearly identical peak loads, but the concrete containing basalt is able to sustain a maximum deflection that is nearly three times greater. The difference in the areas under the curves translates into a significantly higher fracture energy for the basalt concrete than for the limestone
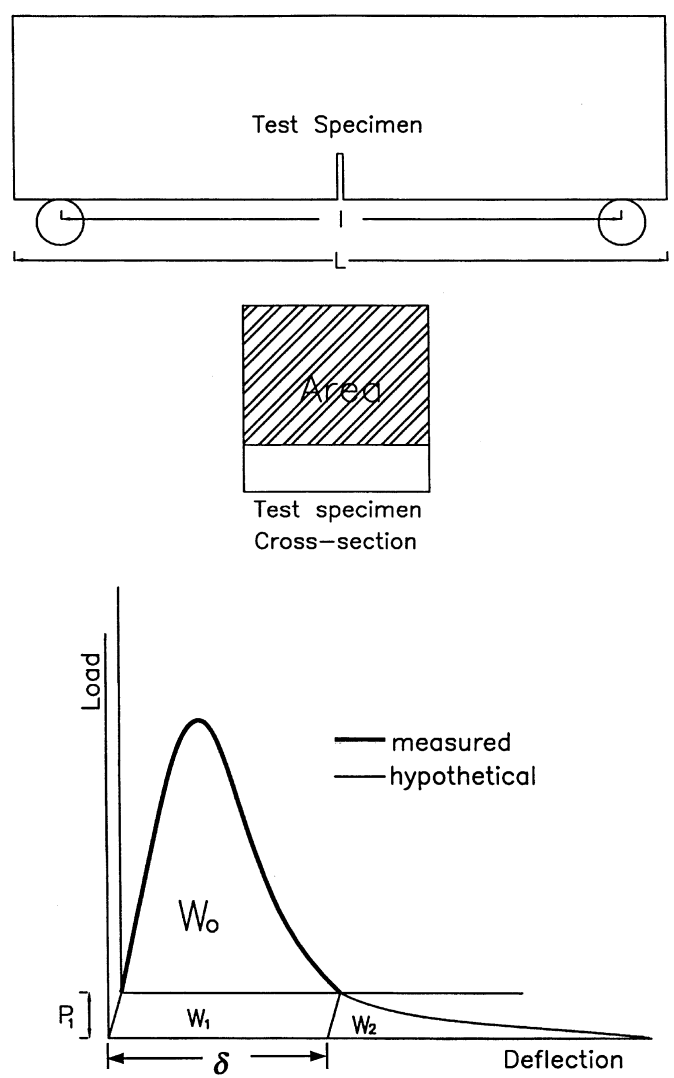

Fig. 4-Schematic of fracture energy test specimen (depth $=$ width $=100 \mathrm{~mm}$ [4 in.]; notch depth $=25 \mathrm{~mm}[1 \mathrm{in}.] ; L=$ $350 \mathrm{~mm}$ [14 in.]; l=300 $\mathrm{mm}$ [12 in.]); and load-deflection curve.

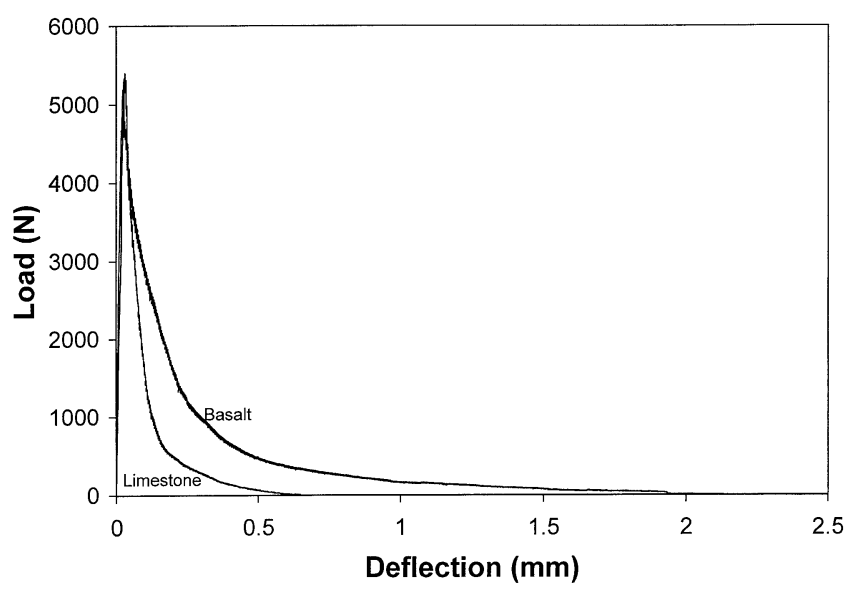

Fig. 5-Load-deflection curves for fracture specimens containing $12 \mathrm{~mm}(1 / 2 \mathrm{in}$.) basalt and limestone normalstrength concretes $(N B-12 h$ and $N L-12 h)(1 N=0.225 \mathrm{lb}, 1$ $m m=0.0394$ in. $)$.

concrete: $193 \mathrm{~N} / \mathrm{m}(1.10 \mathrm{lb} / \mathrm{in}$.) versus $70 \mathrm{~N} / \mathrm{m}(0.40 \mathrm{lb} / \mathrm{in}$.). As will be demonstrated, $G_{f}$ is principally a function of coarse aggregate properties and is largely independent of age and $w / \mathrm{cm}$.

Figure 6 compares the load-deflection curves from fracture tests of high and normal-strength specimens containing basalt in Series I. The high-strength concrete specimen exhibits a significantly higher peak load (9 versus $5.6 \mathrm{kN}$ ), while the normal-strength specimen exhibits more ductile behavior on the descending branch of the curve and a greater 


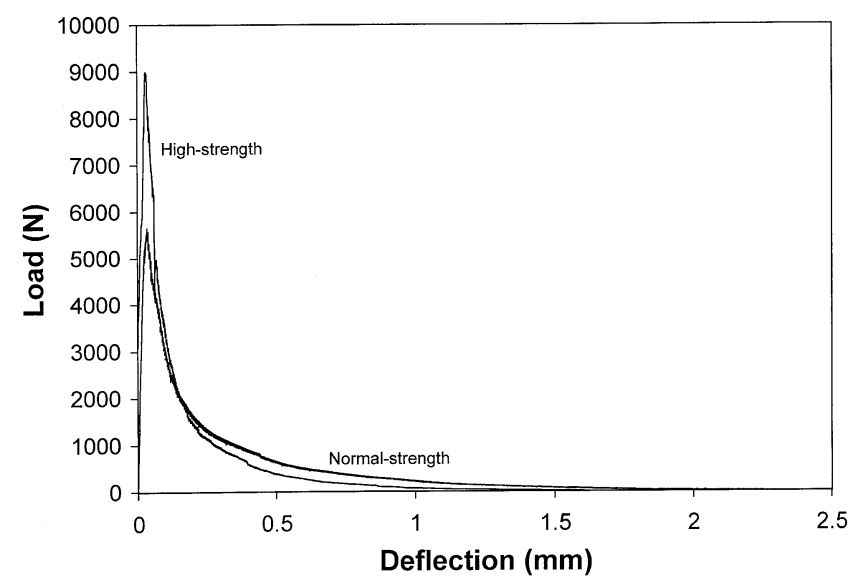

Fig. 6-Load-deflection curves for fracture specimens fabricated with normal and high-strength concretes containing $12 \mathrm{~mm}$ (1/2 in.) basalt coarse aggregate (HB-12l.2 and NB12l) $(1 \mathrm{~N}=0.225 \mathrm{lb}, 1 \mathrm{~mm}=0.0394 \mathrm{in}$. $)$.

maximum deflection. Overall, the areas under the two curves are similar, with $G_{f}$ actually higher for the normal-strength concrete than for high-strength concrete: 182 versus $158 \mathrm{~N} / \mathrm{m}$ (1.05 versus $0.90 \mathrm{lb} / \mathrm{in}$.).

The observations obtained for specific specimens in Fig. 5 and 6 can be generalized, as demonstrated in Fig. 7, in which fracture energy is compared with the $w / \mathrm{cm}$ and age for the specimens in Series II. The figure shows that the fracture energy of the concretes containing basalt is consistently more than two times greater than the fracture energy of the concretes containing limestone. It also demonstrates that fracture energy is nearly constant as a function of $w / \mathrm{cm}$ and age (in this case, for ages of 7 to 180 days). In fact, on the average, the concretes with the lowest $w / \mathrm{cm}$ ratios exhibit the lowest values of $G_{f}$. Similar results are obtained for Series I (Table 2[a]).

The failure surfaces in the fracture tests were similar to those in the compression and flexure tests. The high-strength concrete specimens containing limestone had the smoothest surfaces, while the normal-strength specimens containing basalt had the roughest.

\section{Comparisons of properties}

Flexural strength versus compressive strength-The relationship between flexural strength (modulus of rupture $R$ ) and compressive strength has been well researched. ACI Committee 363 (1992) developed the following expression to describe this relationship for $21 \mathrm{MPa}(3000 \mathrm{psi}) \leq f_{c}{ }^{\prime} \leq 83$ $\operatorname{MPa}(12,000 \mathrm{psi})$.

$$
\begin{gathered}
R=0.94 f_{c}^{\prime 0.5}(\mathrm{MPa}) \\
R=11.7 f_{c}^{\prime 0.5}(\mathrm{psi})
\end{gathered}
$$

The results of this study are plotted, along with Eq. (4), in Fig. 8. (Note: Eq. [4] is based on compressive specimens with height-width ratios of $2: 1$, which typically yield slightly higher strengths than the 3:1 ratio specimens used in this study, and on flexural strengths for specimens under thirdpoint loading, which give slightly lower strengths than the center-point loading used in this study.) The modulus of rupture $R$ increases almost linearly with compressive strength for the concrete containing basalt coarse aggregate, while the

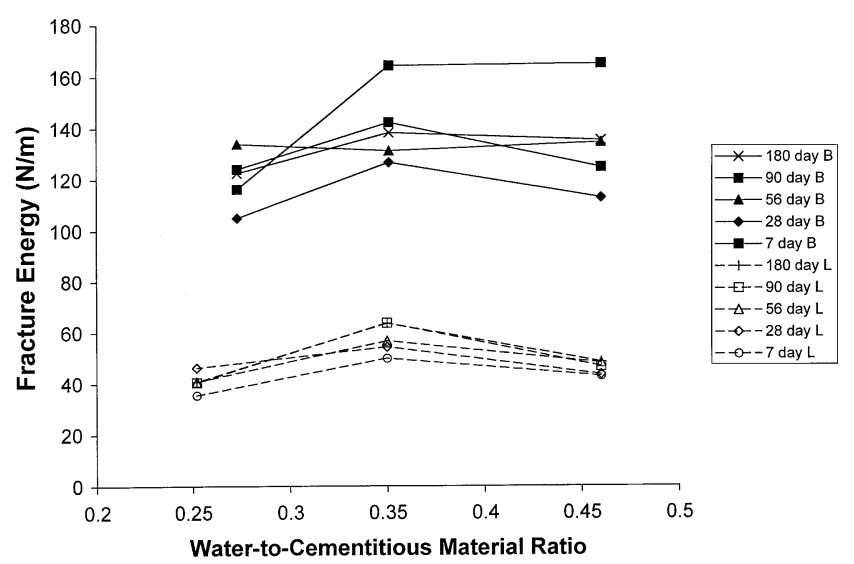

Fig. 7-Average fracture energy versus average $\mathrm{w} / \mathrm{cm}$ for concretes in Series II ( $B=$ basalt; $L=$ limestone $)(1 \mathrm{~N} / \mathrm{m}=$ $5.7 \times 10^{-3} \mathrm{lb} / \mathrm{in}$.).

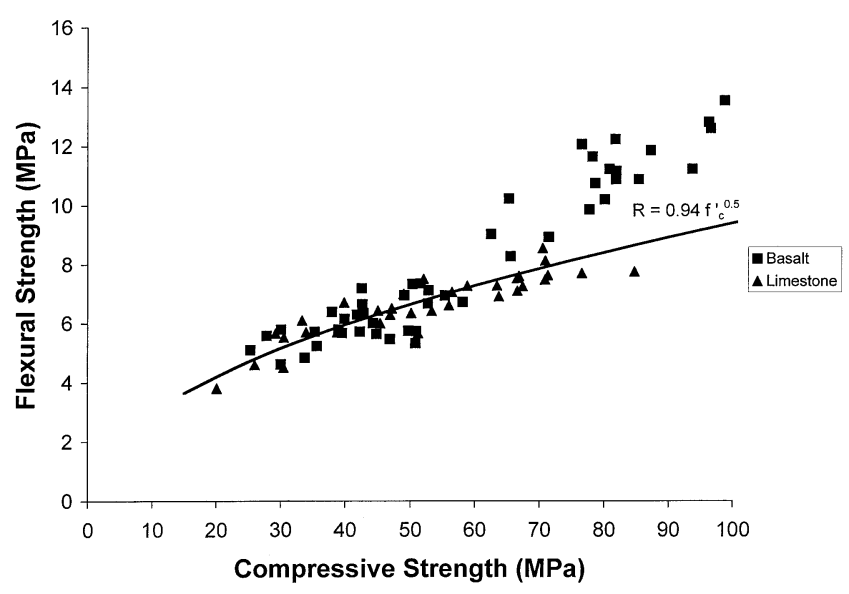

Fig. 8-Flexural strength (modulus of rupture) versus compressive strength for concretes in Series I and II (curve developed by ACI Committee 363 [1992]) (1 MPa = 145 psi).

data points for the limestone concrete follow Eq. (4). As discussed previously, the two coarse aggregates yield similar flexural strengths for the normal and medium-strength concretes, while the basalt yields significantly higher flexural strength than limestone for high-strength concrete.

Fracture energy versus compressive strength-Figure 9 compares fracture energy with compressive strength for all specimens in the study. As suggested in Fig. 7, fracture energy shows no clear relationship to compressive strength. If there is a trend, it is, at most, a slight drop in $G_{f}$ with increasing $f_{c}^{\prime}$. Figure 9 shows that fracture energy depends primarily on aggregate type, with the concretes containing basalt yielding significantly higher fracture energies than the concretes containing limestone. This compares favorably with research by Jensen and Hansen (2001), who observed a dependence of fracture energy on aggregate type and independence from compressive strength for concretes with compressive strengths up to approximately $50 \mathrm{MPa}$ (7000 psi). Zhong and $\mathrm{Wu}$ (2001) also observed the independence of compressive strength and fracture energy for concretes with cube strengths up to $114 \mathrm{MPa}(16,500 \mathrm{psi})$. Other researchers have observed only small changes in $G_{f}$ with increases in $f_{c}{ }^{\prime}$. Get- 


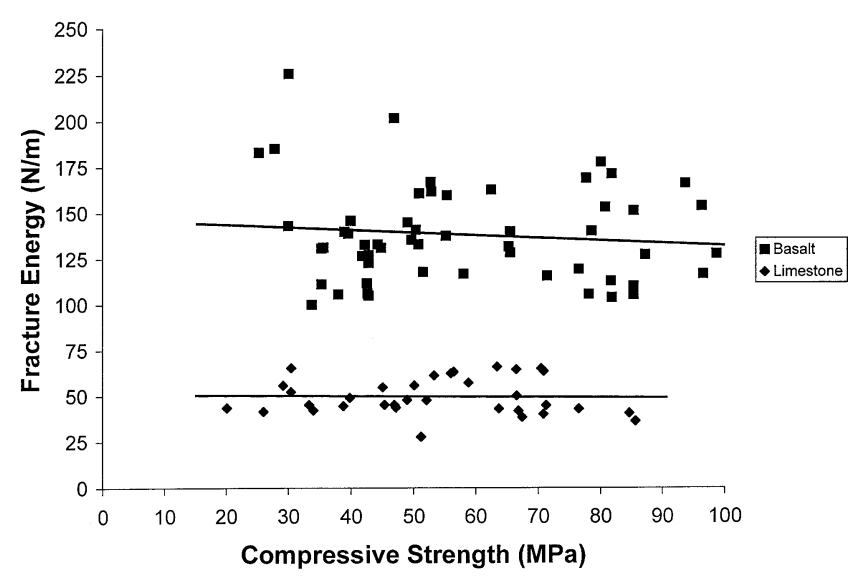

Fig. 9-Fracture energy versus compressive strength for concretes in Series I and II $\left(1 \mathrm{~N} / \mathrm{m}=5.7 \times 10^{-3} \mathrm{lb} / \mathrm{in}\right.$., $1 \mathrm{MPa}$ = 145 psi).

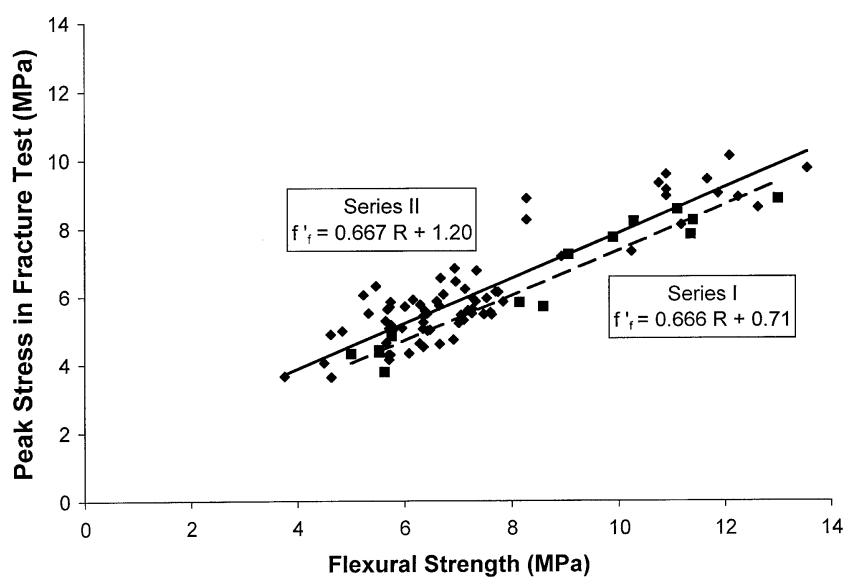

Fig. 10-Peak stress in fracture tests versus flexural strength for concretes in Series I and II (1 MPa = 145 psi).

tu, Ba ant, and Karr (1990) found that an increase in compressive strength of $160 \%$ resulted in an increase in fracture energy of only $12 \%$. Giaccio, Rocco, and Zerbino (1993) observed that fracture energy increased as compressive strength increased, but only at a fraction of the rate. Xie, Elwi, and MacGregor (1995) found increases in compressive strength of 29 and $53 \%$ resulted in fracture energy increases of only 11 and 13\%, respectively. Zhou, Barr, and Lydon (1995) found that fracture energy increased or decreased with an increase in compressive strength, depending on the aggregate.

Peak bending stresses in fracture tests versus flexural strength-The peak stresses in the fracture tests $f_{f}^{\prime}$ are calculated using the peak load and net section at the plane of the notch. The peak stresses in the fracture tests are compared to flexural strength $R$ in Fig. 10. As shown in the figure, the two values of stress are nearly linearly related. The relationships shown in Fig. 10 are of some importance because, based on the close relationship between flexural strength and compressive strength (Fig. 8), peak fracture stress will increase with compressive strength. This observation leads directly to an explanation of the performance of high-strength concrete members in tension.

\section{Problems with high-strength concrete}

Figure 9 and 10 are useful in understanding problems related to the fracture properties of high-strength concrete. As shown in Fig. 9, high and normal-strength concretes have similar fracture energies. Since high-strength concrete has dissipated more of its fracture energy by the time it has reached the peak tensile stress, it has less energy available to slow crack propagation once the stress begins to drop (softening portion of the curve [Fig. 6]). This, coupled with the fact that high-strength concrete has a higher driving force (strain energy stored at the peak load), results in more rapid crack growth and more brittle failure than in normal-strength concrete. Thus, although the tensile strength of concrete increases along with compressive strength (at least with $\sqrt{f_{c}^{\prime}}$ ), the lower capability of the higher-strength material to prevent crack propagation results in a lower rate of increase in structural capacity. These observations largely explain the relatively poor performance of high-strength concretes in structural applications in which the tensile properties of the concrete play an important role, such as bond between reinforcing steel and concrete (Zuo and Darwin 2000) and shear (Collins and Kuchma 1999).

\section{CONCLUSIONS}

The following conclusions are based on the tests and evaluations presented in this paper.

1. High-strength concrete containing high-strength aggregate, such as basalt, has higher compressive and flexural strengths than concrete with a similar $w / \mathrm{cm}$ and a weaker aggregate, such as limestone. The compressive and flexural strengths of medium and normal-strength concretes are little affected by the strength of aggregate;

2 . The fracture energy of concrete is governed principally by the properties of the coarse aggregate, with higherstrength aggregates producing concretes with higher fracture energies;

3. For concretes at least five days old, fracture energy is independent of compressive strength, $w / \mathrm{cm}$, and age;

4. There is a close relationship between the peak bending stresses in fracture and flexural test specimens; and

5. Overall, as the compressive strength of concrete increases, the energy stored in the material at the peak tensile load increases, while the ability of the material to dissipate energy remains approximately constant. The result is increasingly brittle behavior as compressive strength increases.

\section{ACKNOWLEDGMENTS}

This paper is based on research supported by the National Science Foundation under Research Grant No. CMS-9402563, the U.S. Department of Transportation Federal Highway Administration, and the Lester T. Sunderland Foundation. Silica fume and chemical admixtures were provided by Master Builders Technologies. Portland cement and fly ash were provided by Lawrence Ready Mix. The basalt coarse aggregate was supplied by Geiger Ready-Mix and Iron Mountain Trap Rock Co. Additional support was provided by Dayton Richmond. A summary of this research was presented in a Keynote Speech at the Fall 2000 Convention of the Korea Concrete Institute (Darwin 2000)

\section{REFERENCES}

ACI Committee 363, 1992, "State-of-the-Art Report on High-Strength Concrete (ACI 363R-92)," ACI Manual of Concrete Practice, 1997 Edition, Part 1, American Concrete Institute, Farmington Hills, Mich.

Ahmad, S. H. and Shah, S. P., 1985, "Standard Properties of High Strength Concrete and Its Implications for Precast Prestressed Concrete," PCI Journal, V. 30, No. 6, Nov.-Dec., pp. 92-119.

ASTM C 39-96, 1996, "Standard Test Method for Compressive Strength of Cylindrical Concrete Specimens," American Society for Testing and Materials, West Conshohocken, Pa., 5 pp.

ASTM C 293-94, 1994, "Standard Test Method for Flexural Strength of Concrete (Using Simple Beam with Center-Point Loading)," American Society for Testing and Materials, West Conshohocken, Pa., 3 pp. 
Barham, S., and Darwin, D., 1999, "Effects of Aggregate Type, Waterto-Cementitious Material Ratio, and Age on Mechanical and Fracture Properties of Concrete," SM Report No. 56, University of Kansas Center for Research, Lawrence, Kans., 95 pp.

Collins, M. P., and Kuchma, D., 1999, "How Safe Are Our Large, Lightly Reinforced Concrete Beams, Slabs, and Footings?" ACI Structural Journal, V. 96, No. 4, July-Aug., pp. 482-490.

Darwin, D.; Tholen, M. L.; Idun, E. K.; and Zuo, J., 1996a, "Splice Strength of High Relative Rib Area Reinforcing Bars," ACI Structural Journal, V. 93, No. 1, Jan.-Feb., pp. 95-107.

Darwin, D.; Zuo, J.; Tholen, M. L.; and Idun, E. K., 1996b, "Development Length Criteria for Conventional and High Relative Rib Area Reinforcing Bars," ACI Structural Journal, V. 93, No. 3, May-June, pp. 347-359.

Darwin, D., 2000, "Fracture of High-Strength Concrete: Implications for Structural Applications," Proceedings, Korea Concrete Institute, V. 12, No. 2, pp. 11-30.

Gettu, R.; Ba ant, Z. P.; and Karr, M. E., 1990, "Fracture Properties and Brittleness of High-Strength Concrete," ACI Materials Journal, V. 87, No. 6, Nov.-Dec., pp. 608-617.

Giaccio, G.; Rocco, C.; Violini, D.; Zappitelli, J.; and Zerbino, R., 1992 "High-Strength Concretes Incorporating Different Coarse Aggregates," ACI Materials Journal, V. 89, No. 3, May-June, pp. 242-246.

Giaccio, G.; Rocco, C.; and Zerbino, R., 1993, "The Fracture Energy $\left(G_{F}\right)$ of High-Strength Concretes," Materials and Structures, V. 26, No. 161, Aug.-Sept., pp. 381-386.

Hillerborg, A., 1985, "The Theoretical Basis of a Method to Determine the Fracture Energy $G_{f}$ of Concrete," Materials and Structures, V. 18, No. 106, pp. 291-296.

Jensen, E. A., and Hansen, W., 2001, "Fracture Energy Test for Highway
Concrete-Determining the Effect of Coarse Aggregate on Crack Propagation Resistance," Transportation Research Record 1730, pp. 10-16.

Kaplan, M. F., 1959, "Flexural and Compressive Strength of Concrete as Affected by the Properties of Coarse Aggregate," ACI Journal, Proceedings V. 30, No. 11, Nov., pp. 1193-1208.

Kozul, R., and Darwin, D., 1997, "Effects of Aggregate Type, Size, and Content on Concrete Strength and Fracture Energy," SM Report No. 43, University of Kansas Center for Research, Inc., Lawrence, Kans., 85 pp.

Ozturan, T., and Cecen, C., 1997, "Effects of Coarse Aggregate Type on Mechanical Properties of Concretes with Different Strengths," Cement and Concrete Research, V. 27, No. 2, Jan., pp. 165-170.

RILEM, 1985, TC 50-FMC, Fracture Mechanics of Concrete, "Determination of the Fracture Energy of Mortar and Concrete by Means of ThreePoint Bend Tests on Notched Beams," RILEM Recommendation, Materials and Structures, V. 18, No. 16, pp. 287-290.

Tholen, M. L., and Darwin, D., 1996, "Effects of Deformation Properties on the Bond of Reinforcing Bars," SM Report No. 42, University of Kansas Center for Research, Inc., Lawrence, Kans., 370 pp.

Xie, J.; Elwi, A. E.; and MacGregor, J. G., 1995, "Mechanical Properties of Three High-Strength Concretes Containing Silica Fume," ACI Materials Journal, V. 92, No. 2, Mar.-Apr., pp. 135-145.

Zhong, D., and Wu, K., 2001, "Fracture Properties of High-Strength Concrete," Journal of Materials in Civil Engineering, ASCE, V. 13, No. 1, Jan.-Feb., pp. 86-88.

Zhou, F. P.; Barr, B. I. G.; and Lydon, F. D., 1995, "Fracture Properties of High-Strength Concrete with Varying Silica Fume Content and Aggregates," Cement and Concrete Research, V. 25, No. 3, pp. 543-552.

Zuo, J., and Darwin, D., 2000, "Splice Strength of Conventional and High Relative Rib Area Bars in Normal and High Strength Concrete," ACI Structural Journal, V. 97, No. 4, July-Aug., pp. 630-641. 